\title{
A cluster of HTLV-1 associated tropical spastic paraparesis in Equateur (Zaire): ethnic and familial distribution
}

\author{
K Kayembe, P Goubau, J Desmyter, R Vlietinck, H Carton
}

\begin{abstract}
In Lisala, Equateur province, Zaire, 25 patients from 21 pedigrees were identified with human $\mathrm{T}$-lymphotropic virus type 1 (HTLV-1) associated tropical spastic paraparesis (TSP). In the $10(48 \%)$ pedigrees with additional genuine TSP cases established mainly by history, seven of 10 patients' mothers, no fathers or spouses, one of 59 surviving offspring, five of 105 siblings, and six other close blood relatives had TSP. A child may develop TSP before its mother. Three familial cases were in paternal relatives only. In total, 39 cases (11 men, 28 women) were identified in this population of about 50,000. Half were in the Mundunga minority of $\leqslant 10 \%(p<0.001)$. The data suggest maternal transmission of HTLV -1 and enhanced TSP susceptibility in those infected due to familial, probably genetic factors.
\end{abstract}

Human T-lymphotropic virus type 1 (HTLV-1), the first human retrovirus isolated and a causative agent of adult $\mathrm{T}$-cell leukaemia (ATL), ${ }^{1}$ is also associated with slowly progressive myelopathy, ${ }^{2}$ a disease called tropical spastic paraparesis (TSP) in the tropics, and HTLV-1 associated myelopathy (HAM) in Japan. ${ }^{3}$ Numerous cases of HTLV- 1 associated TSP have been detected in the Caribbean (Martinique, Jamaica, Trinidad), in the Tomaco lowlands on the Pacific coast of Colombia and in the Seychelles. ${ }^{4-8}$ A possible link between these tropical regions is the presence of a population of black African ancestry and where people of different ethnic origin live together, the highest prevalence of anti-HTLV-1 is found amongst the black people. ${ }^{9}$ Thus HTLV-1 could have been imported to these various areas from their African population. This is consistent with a suggested sero-prevalence of HTLV-1 of $1-10 \%$ in African countries (Gabon, Ghana, Ivory Coast, Kenya, Nigeria, Senegal $)^{10-14}$ and with the isolation of HTLV-1 from at least one African patient, a Zairian treated for ATL in France. ${ }^{15}$ However, there are technical problems in obtaining exact seroprevalence data, particularly on stored African sera, ${ }^{1216}$ and the above figure is lower than that in the endemic areas in the Caribbean or Japan. Reported cases of HTLV-1 associated ATL and TSP are conspicuously few in Africans. No clusters of TSP and only four sporadic TSP patients have been reported, two from the Ivory Coast, ${ }^{1718}$ one from Senegal, ${ }^{19}$ and one from Ethiopia. ${ }^{20}$ An extensive serological and neurological survey in Gabon has shown a substantial seroprevalence of HTLV-1, but no TSP cases. ${ }^{21}$

We describe an important cluster of HTLV-1 associated TSP in the tropical rain forest of Equateur province, Zaire, and its striking familial and ethnic distribution.

\section{Material and methods \\ Location of the study}

The study was conducted at the Telema Rehabilitation Centre in Lisala (Zaire) in December 1987. Lisala is located in the Equateur province, on the right bank of the Zaire river, in the tropical rain forest, $2^{\circ}$ north and $22^{\circ}$ east, at a mean altitude of $300 \mathrm{~m}$ (fig 1 ). The city has 30,000 inhabitants, but patients of the neighbouring villages at a distance of up to $20 \mathrm{~km}$ are also treated as outpatients at the Telema Rehabilitation Centre bringing the total population served by the centre to an estimated 50,000. Seventy five per cent of this population are Ngombe, $10 \%$ are Budja, $10 \%$ are Mundunga and 5\% Mongo or other. Most people marry in their own ethnic group but never marry with close relatives.

\section{Study population}

At the Telema Rehabilitation Centre, 28 subjects suspected by the local physiotherapist of having a spastic paraparesis were examined by two neurologists (KK and $\mathrm{HC}$ ) either at the centre or in their homes in the villages surrounding Lisala up to a distance of $20 \mathrm{~km}$. An additional four spastic patients belonging to a family which moved from Lisala to Kinshasa were examined by $\mathrm{KK}$ at the Centre Neuropsychopathologique (CNPP) in Kinshasa. A pedigree covering at least three generations was obtained of all 32 patients examined. The criteria defined by $\operatorname{Roman}^{8}$ and more recently by Arango ${ }^{7}$ were used to identify patients with TSP. However, two important identification criteria proposed by Arango were not taken into account: onset of the disease after 15 years of age and absence of a history of neurological diseases in previous generations. On the contrary, histories were taken and pedigrees were constructed with the aim of identifying relatives with TSP. Serum samples were obtained from 32 paretic patients and CSF from 22 patients. Serum was obtained from 29 neurologically intact blood relatives and two healthy spouses.

Received 16 December and in
} 
Figure 1 Map of Zaire

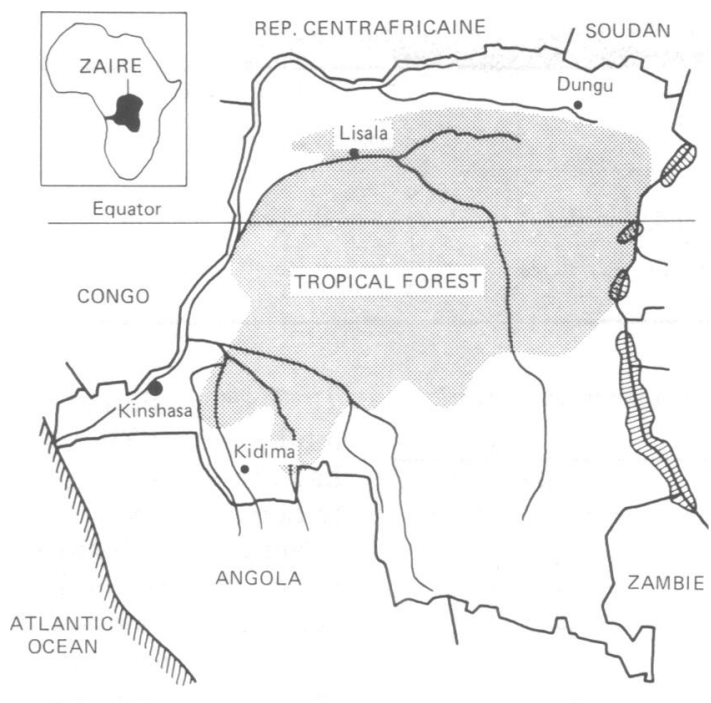

Controls

The seroprevalence of antibodies to HTLV-1 was tested in sera of neurologically intact subjects (NIS) and patients with other neurological or psychiatric disorders than chronic TSP (OND) from different regions of Zaire. Two groups of 100 subjects each were selected on the basis of their HIV status in Dungu, a remote area in Haut-Zaire (fig 1). The second population consisted of 211 mothers with their young children visiting outpatients in Kinshasa. Sera of 119 OND patients were obtained at the Neuropsychiatric Centre as well as serum of 61 patients of the Medical Clinic of the University of Kinshasa. In the analysis patients originating from Equateur are considered separately. Finally 18 patients with acute epidemic spastic paraparesis and three NIS from Kidima and other places in South Bandundu (fig 1) were also tested. ${ }^{22}$

\section{Laboratory tests}

Serum and CSF samples were collected in Lisala and Kinshasa between December 1987 and May 1988 and shipped frozen to Leuven (Belgium). Screening for HTLV-1 antibodies was performed with a commercially available ELISA (DuPont, Wilmington, United States). All positive samples and all samples from TSP patients and their families were also tested by Western blotting (strips from Diagnostic Biotechnology, Singapore). A serum sample was considered positive when reacting with molecular weight bands of $19 \mathrm{kD}$ and $24 \mathrm{kD}$ together with at least one other virus specific band. In fact all samples corresponding to this criterion displayed an almost complete pattern of bands. Samples with virus specific bands other than p19 and p24 or with only one of these two in Western blotting were considered indeterminate. Negative samples displayed no bands or bands outside the specific molecular weights. Indeterminate and negative samples have been grouped in the analysis.

Titres of HTLV-1 antibodies in serum and CSF were defined with an indirect immunofluorescence assay, using a continuous HTLV-1 producing cell-line, MT-2, as the antigen (provided by L Montagnier). Albumin and IgG concentrations were assayed by nephelometry. Isoelectric focusing was performed according to the method described by Delmotte. $^{23}$

All serum samples were also tested for HIV antibodies with two different ELISAs (Wellcome, Dartford, United Kingdom; Abbott, Wiesbaden-Delkenheim, FRG). Positive samples were confirmed by indirect immunofluorescence against HIV-1 and HIV-2 by a competitive ELISA against recombinant core and envelope antigens (Abbott) and by Western blotting for HIV-1 and HIV-2 (strips from Diagnostic Biotechnology).

\section{Results}

Clinical features and presence of anti-HTLV-1 Of 32 patients screened for chronic symmetric spastic paraparesis, 29 had gradual onset of slowly progressive disease (table 1). Among these 29, 26 had clinically typical TSP, and 25 $(96 \%)$ had anti-HTLV-1 in their serum (table 1). In addition to their paraparesis, most of these nine men and 16 women complained of increased urinary frequency or retention and of constipation. Most males complained of impotence. Spastic paraparesis, absence of sensory level and absence of systemic disease were confirmed by examination (table 2). Other features will be discussed below. The seronegative TSP patient also lacked antibody in his CSF, but he had a typical TSP history and presentation.

Three other patients (table 1) also had progressive weakness of the lower limbs, and anti-HTLV-1 in their serum and CSF. In one spastic patient, the main reason for the gait disturbance was cerebellar ataxia. In the two others, proximal weakness of the four limbs and hyporeflexia were present without signs of corticospinal tract, sensory or cerebellar involvement, or bladder or sexual dysfunction. The two patients were unrelated ethnic Ngombe. One was a 55 year old man whose disease had started a year earlier. He was the sole child of nonconsanguineous parents and there was no similar disease or TSP in his blood relatives. The other patient, aged 52 years, also had onset of disease a year before and had nonconsanguineous parents. These, his eight siblings and 12 children did not have similar disease or TSP, but a half brother from the same father had TSP. The remaining three patients had HTLV-1 negative spastic paraparesis with a history of incompletely recovered acute myelopathy, one traumatic, one post-infectious and one of unknown origin.

Familial and epidemiological features of HTLV-1 positive TSP

The 25 HTLV-1 positive patients first identified were from 21 families that were not closely related. Four relatives indicated by them as having the same disease could be examined, and they had HTLV-1 positive TSP. Of the 25 patients, 13 (10 pedigrees) were ethnic Mundunga, 11 (10 pedigrees) were Ngombe and one was Budja. Since the Mundunga constitute less than $10 \%$ of the Lisala population, this indicates strong ethnic clustering $(p<0.001)$. Half of the patients lived in 
Table 1 Lisala patients screened for chronic symmetric spastic paraparesis

\begin{tabular}{|c|c|c|c|c|c|}
\hline \multirow[b]{2}{*}{ Clinical features } & \multirow[b]{2}{*}{ Number } & \multicolumn{2}{|c|}{$H T L V-1$-pos } & \multirow{2}{*}{$\begin{array}{l}\text { Oligoclonal } \\
\text { IgG banding } \\
\text { in CSF }\end{array}$} & \multirow[b]{2}{*}{$H I V-1$-pos serum } \\
\hline & & Serum & $C S F$ & & \\
\hline 1. Slowly progressive paresis & 29 & & & & \\
\hline Spastic paraparesis + sphincter dysfunction & 26 & 25 & $13 / 16$ & $13 / 14$ & 0 \\
\hline Paraparesis + cerebellar ataxia & 1 & 1 & $1 / 1$ & 1 & 0 \\
\hline Quadriparesis + proximal atrophy + areflexia & 2 & 2 & $2 / 2$ & 2 & 0 \\
\hline 2. Sequelae of acute myelopathy & 3 & 0 & $0 / 3$ & 0 & 0 \\
\hline
\end{tabular}

Table 2 Neurological findings in 25 patients with HTLV-1-positive tropical spastic paraparesis

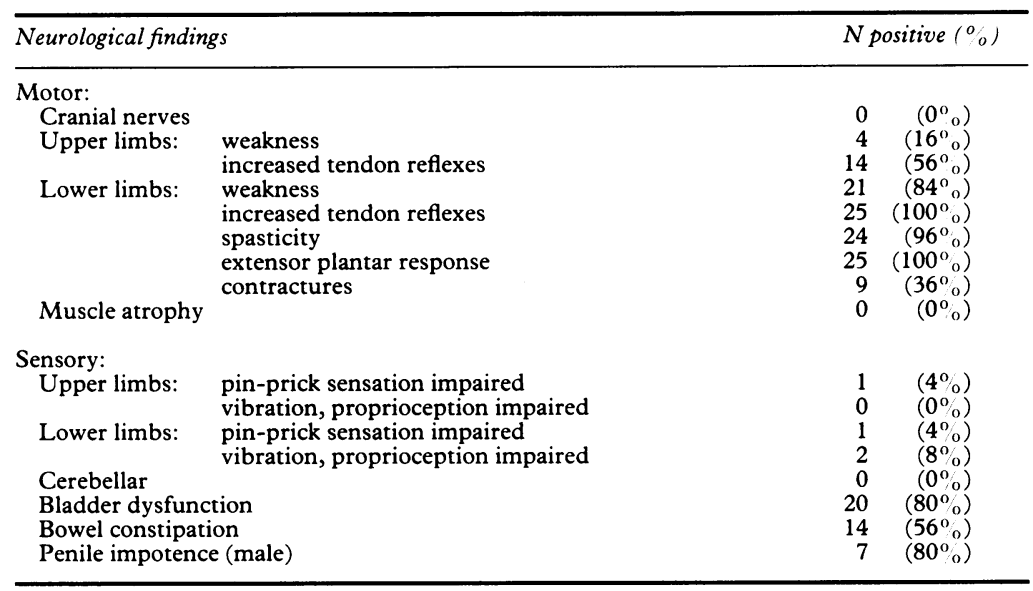

Figure 2 Year of onset (upper graph) and age at onset (lower graph) of 25 cases of $H T L V-1$ positive tropical spastic paraparesis.
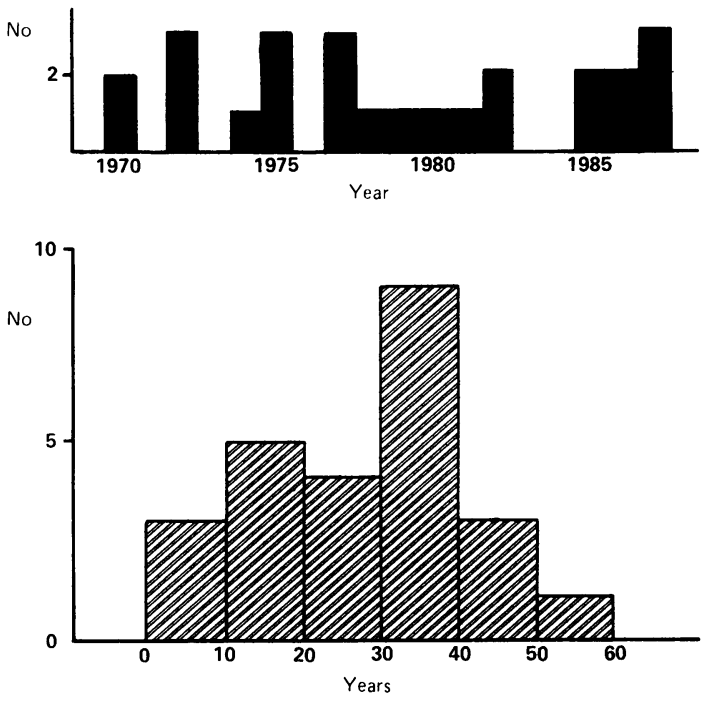

Lisala city, and half along paths in the rain forest. No patient lived close to another, except for a mother and a daughter both with TSP in the same house. No patient had received blood transfusions. Ages were between 11 and 55 years, median 35 (fig 2). Age of onset was between 7 and 51 years, median 31 (fig 2). The median disease duration before the patients needed aid for walking was nine years. They became unable to walk after a median of 13 years and the longest disease course was 17 years.

Familial occurrence of TSP was established in close relatives by examination (see above), or by history only. We consider the histories highly reliable, given the typical course and presentation of the disease, and these histories proved correct in the four patients we could examine. Familial cases were found in 10 of the
21 TSP pedigrees. In seven pedigrees, the mother of a TSP case had died of TSP or still had the disease (figs 3 and 4). None of the 21 fathers had TSP.

Serum was obtained from two neurologically intact fathers, and one had anti-HTLV-1. When both mother and child had TSP, it usually occurred much earlier in the mother, but in two cases, TSP had started in the child five and nine years before the mother; in one case, it started the same year. Age of onset was not different in seven patients whose mother had TSP and in 11 patients whose mother was alive and well.

Five out of 105 siblings of the 25 patients had TSP. One of their 59 living children had TSP. None of the 15 regular spouses of the 25 patients had TSP. Ten spouses of TSP patients not examined by us, but from the same pedigrees, did not have TSP.

\section{Serology}

The CSF of 18 seropositive patients (15 TSP, one cerebellar ataxia, two with muscle atrophy) were examined. HTLV-1 antibodies were present in all but two CSF samples, with almost complete Western blot patterns similar to those in serum (see examples on fig 5). The two patients without HTLV-1 antibodies in their CSF were moderately disabled with typical TSP for seven and nine years.

Increased IgG/albumin ratios and oligoclonal banding of IgG on isoelectrofocusing were present in all HTLV-1 positive CSF samples. No relationship was found between the $\mathrm{IgG} /$ albumin ratios and the severity or duration of the disease.

Seven paired CSF and serum samples could be further investigated (six typical TSP and one with cerebellar ataxia). All had an intact blood-brain barrier as shown by normal serum/ CSF albumin ratios (lowest was 181, normal values $\geqslant 105$ ). Specific CSF anti-HTLV-1 antibody titres by immunofluorescence were 10 to 40 . Six patients had a serum/CSF specific antibody ratio of 5 to 40 (normal values: 150 750) indicating intrathecal anti-HTLV-1 production. ${ }^{24}$ On this basis, intrathecal synthesis could not be demonstrated in one TSP patient (ratio: 320 ).

Anti-HTLV-1 antibodies were found in 18 out of $29(62 \%)$ neurologically intact first or second degree blood relatives of TSP patients. Among these $4 / 8$ children of affected mothers, $5 / 8$ siblings and $1 / 2$ fathers of TSP patients were seropositive. One tested husband and two children of a father with TSP were seronegative. Two wives of TSP patients were both positive.

The results of screening for HTLV-1 
Figure 3 Pedigrees of eight families with more than one member affected by tropical spastic paraparesis.
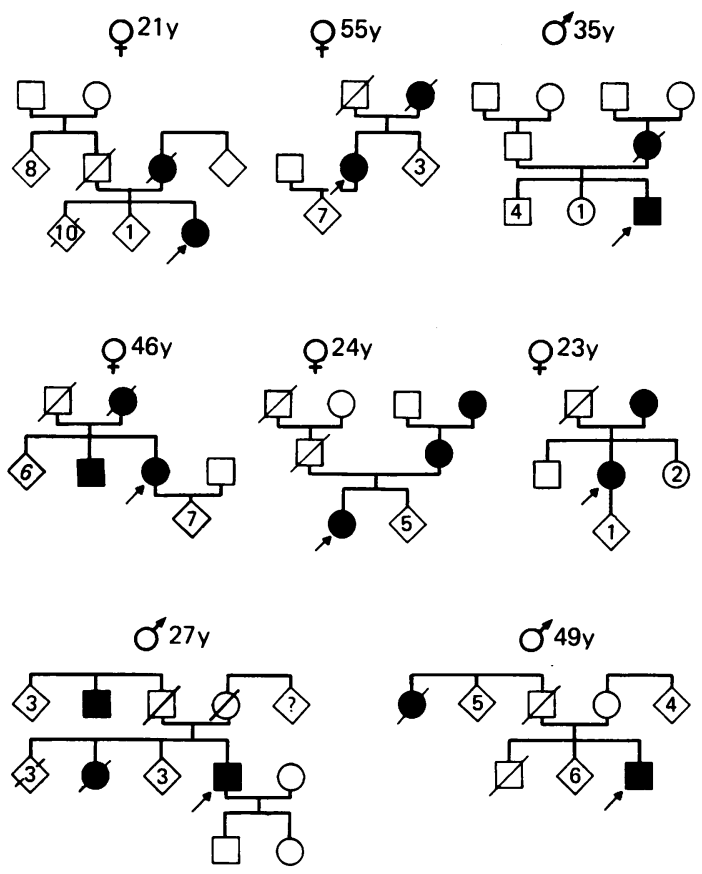

Table 3 HTLV-1 seroprevalence in Zairian reference groups

\begin{tabular}{|c|c|c|}
\hline & $\begin{array}{l}\begin{array}{l}\text { Neurologically } \\
\text { intact } \\
\text { subjects }\end{array} \\
\end{array}$ & $\begin{array}{l}\text { Non-TSP } \\
\text { neurological } \\
\text { diseases }\end{array}$ \\
\hline & $N$ pos $/ N$ tested & $N$ pos $/ N$ tested \\
\hline $\begin{array}{l}\text { Dungu (1987-88): } \\
\text { HIV-negative } \\
\text { HIV-positive }\end{array}$ & $\begin{array}{l}2 / 100 \\
6 / 100\end{array}$ & $\begin{array}{l}\text { NA } \\
\text { NA }\end{array}$ \\
\hline \multirow{3}{*}{$\begin{array}{l}\text { Kinshasa (1986-88): } \\
\text { mothers of young children } \\
\text { patients admitted to hospital } \\
\text { (not from Equateur) } \\
\text { patients admitted to hospital } \\
\text { (originating from } \\
\text { Equateur) }\end{array}$} & $8 / 211$ & NA \\
\hline & $1 / 51$ & $8 / 109$ \\
\hline & $2 / 10$ & $2 / 10$ \\
\hline South Bandundu (1986) & $0 / 3$ & $0 / 18$ \\
\hline
\end{tabular}

*Various neurological diseases in Kinshasa; acute epidemic spastic paraparesis in South Bandundu. antibodies in various groups are given in table 3. In inhabitants of the Dungu the prevalence of HTLV-1 tends to be somewhat higher in HIV-seropositive subjects $(6 \%)$ than in HIVseronegative subjects $(2 \%)$, but numbers are too small to reach the significance level. Eight out of 211 mothers tested in Kinshasa had antiHTLV-1 antibodies. Among a group of 20 patients admitted to hospital in Kinshasa, originating from the Equateur province, four were HTLV-1 positive $(20 \%)$ while there were nine seropositives among 160 other patients $(5.6 \%)(p=0.034$, Fisher's exact test). The diagnosis of 10 seropositive OND patients was epilepsy, subacute sclerosing panencephalitis, senile dementia, facial palsy, trypanosomiasis in one patient each and five had less well defined (neuro)psychiatric illnesses. All patients from Bandundu with acute epidemic spastic paraparesis were seronegative.

HTLV-1 antibody titres by immunofluorescence in serum of TSP patients, of their healthy seropositive family members and of seropositive OND patients are presented in table 4. Two thirds of TSP patients had titres $\geqslant 400$, whereas all of the OND in Kinshasa had titres below 400 .

No relationship was found between HIV seropositivity and the presence of HTLV-1 antibodies or HTLV-1-associated disease. None of the paretic patients examined nor any of their family members and none of the controls from Equateur but seen in Kinshasa (table 3) and none of the South Bandundu controls had anti-HIV. One out of eight HTLV-1 positive mothers $(12.5 \%)$ and 17 out of 203 HTLV-1 negative mothers $(8.5 \%)$ had anti-HIV $(p>0 \cdot 1)$. In the patients admitted to hospital in Kinshasa but not from Equateur, anti-HIV was found in $12 \mathrm{HTLV}-1$ negatives (six with and six without neurological disease) and in one HTLV-1 positive with herpes zoster and facial palsy.
Figure 4 Pedigree of the $M$ family from Lisala, examined at Kinshasa.
M. FAMILY 
Table 4 HTLV-1 immunofluorescence antibody titres in different groups

\begin{tabular}{lllllll}
\hline & \multicolumn{3}{l}{ Anti-HTLV-1 antibody titres } & & \\
\cline { 2 - 7 } Subjects & 50 & 100 & 200 & 400 & $\geqslant 800$ & N total \\
\hline TSP^ Lisala & - & 5 & 3 & 6 & 10 & 24 \\
Healthy relatives of TSP, Lisala & 1 & 6 & 3 & 5 & - & 17 \\
OND† Kinshasa & 5 & 3 & 1 & - & & 9 \\
\hline
\end{tabular}

‡Tropical spastic paraparesis.

†Patients with other neurological diseases.

Figure 5 HTLV-1

Western blot patterns in paired serum and spinal fluid samples of tropical spastic paraparesis patients. Lane a: positive control; lane b: negative control; lanes $c, e, g$ : serum samples of three different patients; lanes $d, f, h:$ spinal fluid samples of same patients.

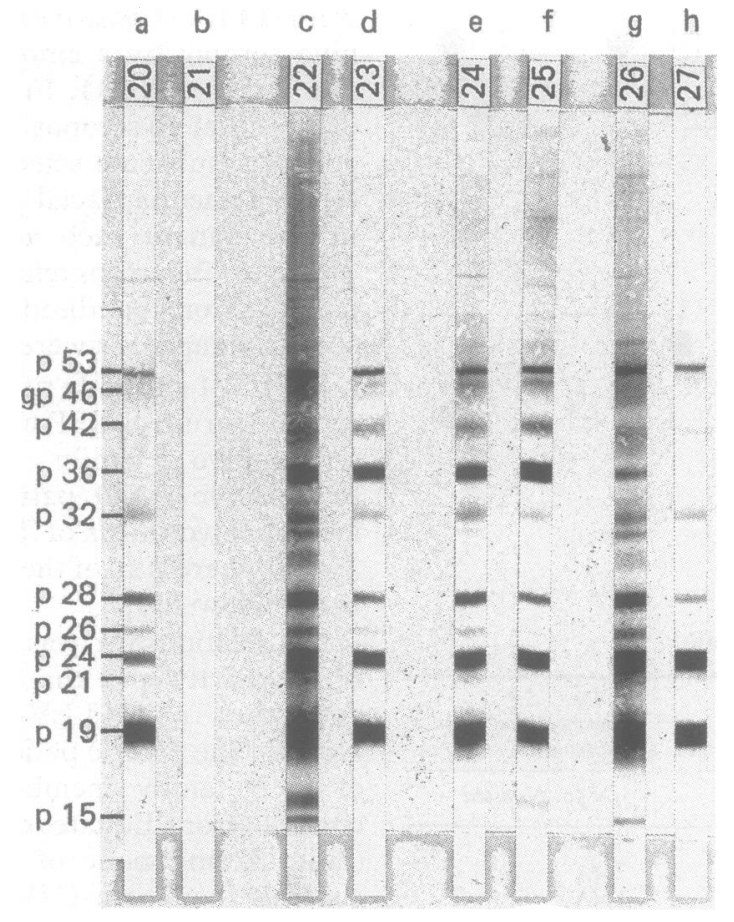

\section{Discussion}

The clinical presentation of typical TSP cases in Lisala is similar to that of TSP in the Caribbean and HAM in Japan. ${ }^{25}$ The HTLV-1 seropositivity in Lisala cases $(96 \%)$ is the highest reported so far for TSP in endemic countries, but all of the 11 patients born in the West Indies and seen in the United Kingdom were seropositive. ${ }^{26}$ Intrathecal synthesis of anti-HTLV-1 occurs in most but not all of the Lisala patients which agrees with similar findings in 14 of $19(74 \%)$ TSP patients of various origin. ${ }^{27}$ One patient had cerebellar signs in addition to the pyramidal syndrome, a combination which has been previously noted ${ }^{5}$ and may be a variant of HTLV-1 associated TSP, particularly since high serum anti-HTLV-1 was associated with intrathecal production of antibody in our patient. In two patients with proximal muscle atrophy of lower and upper limbs and weak or absent tendon reflexes, clinical examination could not distinguish between neurogenic or myopathic atrophy. Although both had anti-HTLV-1 in the serum and CSF, it remains to be seen whether this is another expression of HTLV-1 associated myelopathy or a coincidence.

The Telema outpatient facility reaches an estimated population of 50,000. Every five years, it sees about seven new cases of TSP, suggesting an annual incidence of three per
100,000. Furthermore a prevalence of at least 50 cases per 100,000 is shown by our study. These figures are almost certainly an underestimate of TSP in the area, with a bias toward the more severe cases. The true incidence and prevalence of HTLV-1 associated TSP, and the geographical extent of the cluster, remains to be established. One pedigree (fig 4) includes HTLV-1 positive TSP patients who had moved from Lisala to Kinshasa. Spot inquiries among hospital physicians in different parts of Zaire did not suggest TSP clusters outside Equateur, but sporadic cases or smaller clusters may have gone unnoticed.

The youngest ages of TSP onset in Lisala were 7,8 and 9 years, and one third of our patients started their disease before age 20 years. In other tropical regions, TSP rarely if ever starts before age $20 .^{25}$ In Japan, HAM has been seen as early as the age of six..$^{25}$ It would appear from our study that case definitions excluding cases with onset before 15 and excluding cases with neurological disease in previous generations ${ }^{78}$ are inappropriate.

HTLV-1 positive TSP was found in the three ethnic groups constituting $95 \%$ of the Lisala population, but half of the cases and of the families with one or more cases were in the Mundunga minority of $10 \%(p<0.001)$. While the other groups are Bantu-speaking and have long been established in Lisala, the Mundunga only arrived about 150 years or six generations ago from Southern Sudan and have kept their Sudanese language. They live in small settlements dispersed among those of the Ngombe majority. Cultural habits which might explain the difference with the other groups were not evident. In Dungu, north-eastern Zaire (table 3), the inhabitants are Azande, a Sudanese-speaking people who also exist in Sudan; their anti-HTLV-1 prevalence was not unusual for Central Africa, and TSP cases have not been reported.

Besides ethnic aggregation, there was a strong familial aggregation of TSP cases in Lisala. The $21 \mathrm{HTLV}-1$ positive TSP cases found by direct search were from 21 different families and they reported $18 \mathrm{TSP}$ cases in first or second degree relatives they knew personally, four of whom we could examine and confirm as HTLV-1 positive TSP. Additional mild or incipient cases may have been overlooked. Ten of the 21 families $(48 \%)$ had more than one TSP case. A survey in the $\mathrm{Kii}$ peninsula of Japan showed four familial cases in 18 patients, ${ }^{28}$ and a survey in the Seychelles showed five familial cases in 21 patients. ${ }^{8}$ Remarkably, evidence for familial clustering does not appear in the data from the Caribbean and Colombia. ${ }^{4-6}$ Familial occurrence of TSP 
and in particular the high rate of occurrence in mothers of TSP patients in Lisala, cannot be explained by HTLV-1 transmission alone, even if all family members were HTLV-1 positive, since the prevalence of TSP in HTLV-1 positives has been estimated at less than one in 1000 in Japan. ${ }^{29}$ In Africa, given the paucity of reported TSP cases among a large population of HTLV-1 positive subjects, it could not possibly be higher.

Strikingly, seven mothers but no fathers of our 21 original TSP cases had TSP (figs 3 and 4). Fathers of other TSP patients in our pedigrees were also free of TSP, and not a single conjugal case was detected. Although most familial associations were through the maternal lineage, three were through the paternal lineage: a paternal uncle or aunt in two male TSP patients (fig 3 ) and a paternal great uncle in a female patient (pedigree not shown). This seems to preclude cofactors which are exclusively maternal in favouring the development of TSP in HTLV-1 infected subjects, unless one accepts incomplete penetrance in the mothers.

HTLV-1 is thought to be transmitted sexually, by blood-to-blood contact and from mother to child at an early age. ${ }^{30}$ The latter has been well shown in epidemiological studies in Japan and could occur transplacentally, intrapartum, or via milk during lactation. ${ }^{31}{ }^{32}$ The few serological data we have (anti-HTLV1 in two healthy mothers of TSP cases and in four of eight healthy children of TSP mothers) are compatible with this mode of transmission, as are the diseased mother-child pairs. If the child is at highest risk of acquiring HTLV-1 from its mother, then it becomes difficult to distinguish cofactors favouring the development of TSP which are of maternal or other origin.

The highest anti-HTLV-1 titres were found in the serum of TSP patients in contrast to the low titres in the healthy HTLV-1 carriers in Kinshasa where TSP is rare, while in healthy family members of TSP patients both high and low titres could be found (table 4). Similarly, high anti-HTLV-1 titres were observed by others in TSP patients compared to their healthy relatives and to ATL patients. ${ }^{33} \mathrm{~A}$ study in Japan ${ }^{34}$ suggests that different HLA haplotypes are associated with HAM and ATL and that these HLA haplotypes may also segregate high and low in vitro responsiveness of lymphocytes to HTLV-1 antigen. Dalgleish et al found, however, no evidence of a relationship between HLA type and seroconversion or disease in a study of West Indian TSP patients and their relatives in the United Kingdom. ${ }^{33}$ Besides a possible immunogenetic background, other genetic cofactors could be involved. The transmission cannot be autosomal recessive, since vertical transmission was very frequent and consanguinity was never present in Lisala. $\mathrm{X}$-linked dominant transmission of the cofactor by itself could explain the female/male ratio of 1.8 , but is not compatible with the finding of TSP in the paternal branch of male TSP patients, since in this hypothesis the father could only transmit the cofactor to a daughter, not a son. A mitochondrial cofactor, transmitted exclusively by the mother, does not explain the few cases of TSP in the paternal branch, nor the skewed sex distribution of TSP cases (nine girls, three boys) in children of TSP mothers. If the cofactor is genetic, it is most likely a polygenetic influence.

Environmental familial factors predisposing toward TSP are entirely speculative. There is also a remote possibility that familial TSP clusters in an area arise from locally evolved HTLV-1 mutants with increased neurovirulence.

There is some evidence that a virus related to HTLV-1 could be involved in multiple sclerosis. ${ }^{35}$ The high frequency of affected mother/ child pairs in familial multiple sclerosis ${ }^{36}$ evokes a comparison with that of familial TSP.

We thank the staff of the Telema Rehabilitation Centre at Lisala for help with this study.

1 Poiesz BJ, Ruscetti FW, Gazdar AF, et al Detection and isolation of type $\mathrm{C}$ retrovirus particles from fresh and cultured lymphocytes of a patient with cutaneous $\mathrm{T}$ cell lymphoma. Proc Natl Acad Sci (USA) 1980;77:7415-9.

2 Gessain A, Barin F, Vernant JC, et al. Antibodies to human $T$ lymphotropic virus type I in patients with tropical spastic paraparesis. Lancet 1985;ii:407-10

3 Osame M, Matsumoto M, Usuku K, et al. Chronic progressive myelopathy associated with elevated antibodies to human $\mathrm{T}$-lymphotropic virus type $\mathrm{I}$ and adult $\mathrm{T}$-cell leukemia-like cells. Ann Neurol 1987;21:117-22.

4 Vernant JC, Maurs L, Gessain A, et al. Endemic tropical spastic paraparesis associated with human T-lymphotropic virus type I: A clinical and seroepidemiological study of 25 cases. Ann Neurol 1987;21:123-30.

5 Rodgers-Johnson P, Morgan O, Mora C, et al. The role of HTLV-1 in tropical spastic paraparesis in Jamaica. Ann Neurol 1988; 23(Suppl.):121-6.

6 Roman GC, Roman LN, Spencer PS, et al. Tropical spastic paraparesis: a neuroepidemiological study in Colombia. Ann Neurol 1985;17:361-5.

7 Arango C, Concha M, Zaninovic V, et al. Epidemiology of tropical spastic paraparesis in Colombia and associated HTLV-1 infection. Ann Neurol 1988;23(Suppl):161-5.

8 Roman GC, Schoenberg BS, Madden DL, et al. Human Tlymphotropic virus type $I$ antibodies in the serum of patients with tropical spastic paraparesis in the Seychelles. Arch Neurol 1987;44:605-7.

9 Miller GJ, Pegram SM, Kirkwood BR, et al. Ethnic composition age and sex together with location and standard of housing as determinants of HTLV-1 infection in an urban Trinidadian community. Int $J$ Cancer 1986;38:801-8.

10 Saxinger W, Blattner WA, Levine $\mathrm{PH}$, et al. Human T-cell leukemia virus (HTLV-1) antibodies in Africa. Science leukemia virus (H)

11 Biggar RJ, Johnson BK, Oster C, et al. Regional variation in prevalence of antibody against human $T$-lymphotropic virus types I and III in Kenya, East Africa. Int J Cancer 1985;35: 763-7.

12 Fleming AF, Maharajan R, Abraham M, et al. Antibodies to HTLV-1 in Nigerian blood donors, their relatives and patients with leukemias, lymphomas and other diseases. Int J Cancer 1986;38:809-13.

3 De-Thé G, Gessain A, Gazzolo L, et al. Comparative seroepidemiology of HTLV-1 and HTLV-III in the French West Indies and some African countries. Cancer Res 1985;45 (suppl):4633-6.

14 Klotz F, Dupouy P, Delaporte E, et al. Clinical manifestations of HTLV-1 on a medical ward at Libreville in Gabon. Proceedings of the First International Congress of Gabon. Proceedings of the First International Con

15 Hahn BH, Shaw GM, Popovic M, et al. Molecular cloning and analysis of a new variant of human T-cell leukemia and analysis of a new variant of human $\mathrm{T}$-cell leukemia
virus (HTLV-1b) from an African patient with adult $\mathrm{T}$ virus (HTLV-1b) from an African patient with adult
cell leukemia/lymphoma. Int $J$ Cancer 1984;34:613-8.

cell leukemia/lymphoma. Int $J$ Cancer 1984;34:613-8.
6 Editorial. HTLV-1 comes of age. Lancet 1988;i:217-9.

17 Gessain A, Francis H, Sonan T, et al. HTLV-1 and tropical Gessain A, Francis H, Sonan T, et al. HTLV-1 and
spastic paraparesis in Africa. Lancet 1986;ii:698.

18 Giordano C, Dumas M, Hugon J, et al. Neuromyélopathies tropicales africaines: 61 cas étudiés en Côte d'Ivoire. Rev Neurol (Paris) 1988;144:578-85.

19 Gout O, Gessain A, Bolgert F, et al. Chronic myelopathies associated with HTLV-1. A clinical, serological and immuno-virological study of ten patients seen in France. Arch Neurol 1989;46:255-60.

20 Ryberg B. Tropical spastic paraparesis associated with human T-lymphotropic type I virus in an east African naturalized in Sweden. Br Med J 1987;295:1380-8.

21 Delaporte E, Dupont A, Peeters M, et al. HTLV-1 
endemism in Gabon. XIIth International Congress for Tropical Medicine and Malaria, Amsterdam, 1988.

22 Carton H, Kazadi K, Kabeya, et al. Epidemic spastic paraparesis in Bandundu (Zaire). $J$ Neurol Neurosurg Psychiatry 1986;49:620-7

23 Delmotte P. Gel isoelectrofocusing of cerebrospinal fluid proteins: a potential diagnostic tool. Zschr Klin Chem Klin Biochem 1971;9:334-6.

24 Mathiesen T, Fridell E, Fredrikson S, et al. Combination ELISA's for antiviral antibodies in CSF and serum in patients with neurological symptoms and in healthy controls. J Virol Methods 1988;19:168-80.

25 Roman GC. The neuroepidemiology of tropical spastic paraparesis. Ann Neurol 1988;23(suppl):113-20.

26 Newton M, Cruickshank K, Miller D, et al. Antibody to human T-lymphotropic virus type 1 in West-Indian-born UK residents with spastic paraparesis. Lancet 1987;i: 415-6.

27 Gessain A, Caudi C, Gout O, et al. Intrathecal synthesis of antibodies to human $T$ lymphotropic virus type $I$ and the presence of IgG oligoclonal bands in the cerebrospinal fluid of patients with endemic tropical spastic paraparesis. $J$ Infect Dis 1988;157:1226-34.

28 Miyai I, Saida T, Fujita M, et al. Familial cases of HTLV-1 associated myelopathy. Ann Neurol 1987;22:601-5.

29 Mori M, Ban N, Kinoshita K. Familial occurrence of HTLV-1-associated myelopathy. Ann Neurol 1988; 23:100.
30 Kajiyama W, Kashiwagi S, Ikematsu $\mathrm{H}$, et al. Intrafamilial transmission of adult $\mathrm{T}$ cell leukemia virus. $J$ Infect Dis 1986;154:851-7.

31 Hino S, Yamaguchi K, Katamine S, et al. Mother-to-child transmission of human T-cell leukemia virus type-I. Jap J transmission of human T-cell leukemian

32 Kinoshita K, Yamanouchi K, Ikeda S, et al. Oral infection of a common marmoset with human $\mathrm{T}$-cell leukemia virus type I (HTLV-1) by inoculating fresh milk of HTLV-1 carrier mothers. Jap J Cancer Res (Gan) 1985;76: 1147-53.

33 Dalgleish A, Richardson J, Matutes E, et al. HTLV-1 infection in tropical spastic paraparesis: lymphocyte culture and serologic response. Aids Research and Human Retroviruses 1988;4: 475-85.

34 Usuku K, Sonoda S, Osame M, et al. HLA haplotype-linked high immune responsiveness against $\mathrm{H} \mathrm{TLV}-1$ in HTLV1-associated myelopathy: comparison with adult TL myelopathy: comparison with adult T-cell leukemia/lymphoma. Ann Neurol 1988;23(suppl)

35 Reddy

Reddy EP, Sandberg-Wollheim M, Mettus RV, et al. Amplification and molecular cloning of HTLV-1 sequences from DNA of multiple sclerosis patients. Science 1989;243:529-33.

36 Ebers GC, Bulman D, Sadovnick AD. Parent/child concordance in multiple sclerosis. Abstract; 39th Annual Meeting of the American Society of Human Genetics, New Orleans. October 12-15, 1988. 